\title{
The Association Between Self-Concept and Self-Efficacy in Patients Under Treatment by Hemodialysis
}

\author{
Marziyeh Jafari ${ }^{1}$; Reza Mannani ${ }^{1, *}$; Kourosh Zarea ${ }^{2}$ \\ ${ }^{1}$ Nursing Department, Nursing and Midwifery School, Khourasgan Branch, Islamic Azad University, Isfahan, IR Iran \\ ${ }^{2}$ Chronic Disease Care Research Center, Jundishapur University of Medical Sciences, Ahvaz, IR Iran \\ *Corresponding author: Reza Mannani, Nursing Department, Nursing and Midwifery School, Khourasgan Branch, Islamic Azad University, Isfahan, IR Iran. Tel: +98-9131171826 \\ E-mail: reza@gmail.com
}

Received: January 22, 2015; Revised: March 13, 2015; Accepted: March 17, 2015

Background: Hemodialysis, as one of the most common methods of controlling chronic renal failure, causes the change in the ways of living as well as physical and mental health status and leads to changes in the family and social rolls of the individual. All these factors influence self-concept and self-efficacy to some extent.

Objectives: This study was conducted to analyze the association between self-concept and self-efficacy in the patients under treatment by hemodialysis in the selected hospitals of Jundishapur University of Medical Sciences, Ahvaz, Iran, in 2014.

Patients and Methods: In this descriptive-correlation study, 200 patients under treatment by hemodialysis were selected using convenience sampling method. Data collection was completed using a three-part questionnaire including 1) demographic information and information related to the illness, 2) Beck's self-concept questionnaire, and 3) Sherer self-efficacy questionnaire. All questionnaires were handed to the patients in different shifts and were answered in the presence of the researcher after he explained the methodology and obtained their consent. Finally, data were analyzed using descriptive and inferential statistics using Mann-Whitney U statistics tests, Kruskal-Wallis tests, and Spearman's correlation coefficient in the SPSS 22.

Results: According to the results, a direct and significant correlation was observed between self-efficacy and self-concept, so that with an Increase in self-concept, the self-efficacy increased $(\mathrm{P}<0.05)$. The association of self-efficacy with all demographic variables, except the place of living, was significant. On the other hand, self-concept had significant association only with the variables of duration of treatment, the number of dialysis sessions, and family history of disease.

Conclusions: Although there is an association between self-concept and self-efficacy, developing more regular and detailed programs to promote self-concept, especially self-efficacy of the patients, is needed. Due to the high potentiality of mental and psychologic factors in predicting self-efficacy and performing self-care behaviors, and low level of self-efficacy in these patients, there should be much more attention to educational planning in order to promote self-efficacy. The nurses should increase patients' self-care by designing and implementing patient-focused intervention to improve the self-efficacy and self-perception of these patients, especially in acquiring skill related to self-care.

Keywords: Self-Concept; self-Efficacy; Hemodialysis; Patients

\section{Background}

Proper functioning of the kidneys and urinary tract system is essential for survival. With functioning of the kidney and urinary tract, producing homeostasis in the body by the precise regulation of water and electrolytes, waste excretion, and hormone production is feasible. When the kidneys are unable to excrete metabolic waste and doing self-regulation functions, renal failure may occur. Chronic kidney disease is a major public health problem worldwide (1). End-stage renal disease (ESRD) is the progressive and irreversible impairment of kidney function. During this stage of chronic kidney disease, the accumulation of fluids and electrolytes lead to the uremic syndrome. Without renal replacement therapies, uremic syndrome leads to death. Alternative treatments include hemodialysis, peritoneal dialysis, and kidney transplantation (2) The outbreak of this illness is increasing in the world, so that the average global growth rate in the last five years was $8 \%$. The ESRD is a major health problem in the United States as well. The number of patients on hemodialysis in the United States increases by $7 \%$ annually. Although it can develop in all ages, it is most frequently seen between the ages of 20 to 64 years (1). In Iran, the growth rate of ESRD is higher than the average of global growth rate and is about $12 \%$ per year. Hemodialysis is the most common method of dialysis. Continuous or prolonged dialysis is used to treat ESRD. Patients on hemodialysis should receive regular healthcare for the rest of their lives (usually three times a week, each time three to four hours) (2). Although dialysis can increase the lifespan of the pa-

Copyright @ 2015, Ahvaz Jundishapur University of Medical Sciences. This is an open-access article distributed under the terms of the Creative Commons Attribution-NonCommercial 4.0 International License (http://creativecommons.org/licenses/by-nc/4.0/) which permits copy and redistribute the material just in noncommercial usages, provided the original work is properly cited. 
Jafari M et al.

tient, it cannot alter the natural course of renal disease and fully replace the renal function; as a result, patients experience numerous complications and problems. Disorders associated with hemodialysis include hypertriglyceridemia, congestive heart failure, coronary artery disease, angina, myocardial infarction, gastric ulcers, renal osteodystrophy, malnutrition, infection, neuropathy, hypotension, muscle cramps, bleeding, air embolism, dysrhythmia, chest pain, and non-equilibrium dialysis syndromes. The clinical findings in these patients are non-specific symptoms such as fatigue, lethargy, pruritus, amnesia, loss of sexual desire, and nausea (3). Chronic renal failure (CRF) or ESRD is one of the major causes of death and disability worldwide (4). The outbreak of kidney failure in European countries has increased by $30 \%$ and has an uptrend in Iran as well; it has been predicted that by the year 1400 , there will be over 95 thousand renal patients in Iran. According to statistics, between 2013 - 2014, there were 24 thousand patients on dialysis and in the current year, 5500 new cases have been added to this number; there are currently 24 thousand patients on dialysis and 31 thousand patients have had renal transplantation. In addition, between 2012 - 2013, there were over 446 dialysis units that have been increased to 466 units between 2013 - 2014. According to statistics, about 4000 dialysis machine have been imported, but the number is still low (ministry of health and medical education, 2013). According to statistics received from the specific diseases unit for the treatment deputy of the Jundishapour university of medical sciences, Ahvaz, Iran, there are currently $60 \mathrm{pa}-$ tients on peritoneal dialysis and 1100 patients on hemodialysis in Khuzestan. There are 75 people with renal failure out of every 1 million people. It should be noted that many types of diseases, especially chronic and debilitating ones, have numerous psychiatric consequences (5). Therefore, physical illnesses followed by psychiatric disorders are common. Dialysis and kidney failure are among physical disorders (6). Considering that in the current division, the patients on dialysis are classified as special cases, the patients need emotional support to cope with the current situation. People who have high psychologic and social support can more effectively adapt stressful life events (7). When the patient starts dialysis treatment, his life will be thoroughly changed, he should attend dialysis meetings regularly, use prescribed drugs, and modify anything he eats or drinks. The frequency and duration of dialysis is one of the stressful factors for patients on hemodialysis that affect their area of their mental and social problems (8). Patients on hemodialysis need psychosocial support due to their mental disorders. They also know that their lives depend on hemodialysis and on the other hand, limits and changes in their lives make it difficult for them to continue the treatment program. Patients whose kidneys do not function well can continue their lives for years by dialysis, and although significant progress has been made in medical care for patients with ESRD, their suffering, which is caused by poor quality of life, continues compared to the general population (9). Physiologic changes create psychological stress for the patient, so that most of them do not become compatible with problems and stress (10), and experience numerous behavioral changes such as anxiety, depression, grief, denial of illness, delusions, and hallucinations. In general, patients on hemodialysis live with difficulties (11). A concept of one's "self" is a crucial point to understand people and their behavior. The Self-concept includes the interpersonal experiences, relationships with others, and interactions with the outside world; it has a powerful effect on behavior (12). The results of several studies suggest the involvement of patients with mental health problems. One of the factors affecting mental health is the self-concept. Research suggests a strong association between self-concept and mental health of the patients with chronic diseases (13). In patients on hemodialysis, common stressors include feelings of powerlessness, lack of disease and treatment control, imposed enforcement remedies, limitations caused by the therapeutic regimens, financial problems, physical issues, and inability to hold a job, all of which cause changes in the mental image of the individual. Furthermore, the reduction of physical energy, changes in sexual activity, changes resulting from surgical procedures, the effect of needles, bone disease, and fatigue affect the attitude of patients towards themselves (8). On the other hand, emotional stress may reduce the self-efficacy in patients with chronic diseases by influencing the cognitive-behavioral domain (14). Studies have shown that regulating self-efficacy is effective in modifying health behaviors (15). Therefore, helping patients to adapt to these conditions and supporting them psychosocially are an important part of the nurses' job (16). Considering the above issues, studying self-efficacy and its related elements in patients on hemodialysis seems necessary.

\section{Objectives}

This study was conducted to analyze the association between self-concept and self-efficacy in the patients on hemodialysis in the selected hospitals of Ahvaz University of Medical Sciences, Ahvaz, Iran, during 2014.

\section{Patients and Methods}

In this descriptive correlational study, 200 patients on hemodialysis, who were referred to Golestan, Razi, and Imam Khomeini hospitals and had the inclusion criteria, were included. Inclusion criteria were as follows:

Willingness to participate in the study, age of 18 to 75 years, Iranian nationality, faith in Islam, having an active file in the hospital, the lack of physical or mental disability, lack of physical and mental illness during the study, lack of exposure to life crisis in the past six months, starting hemodialysis for at least three months, 
doing hemodialysis at least twice or three times a week, not having kidney transplant, and not being on the kidney transplant list. The patients were excluded from the study if they did not want to participate anymore for any reason or if they had not answered the questionnaire completely.

The tool for data collection in this study was questionnaire. The questionnaire used in this study consists of three parts and 57 questions. The first part of the questionnaire was personal information and disease characteristics and consisted of 17 questions about the variables of age, sex, education, marital status, duration of hemodialysis treatment, the number of hemodialysis per week, the cause of chronic renal failure, and duration of illness. In the second part of the questionnaire, the Beck's standard self-concept questionnaire was used to measure self-concept and in the third part, Sherer et al. Al questionnaire was used to measure the self-efficacy (1982). Beck's self-concept questionnaire is a self-report instrument developed in 1989 by Beck et al. in which individuals' answering to this questionnaire is based on his assessment in comparison with other people they know. This test measures the physical attractiveness, job effectiveness, disadvantages, advantages, and mental ability. In Iran, it was first used in 1994 by Nabavi, in Tehran, and the internal consistency of $80 \%$ and test-retest correlation coefficient of $88 \%$ was reported (17). The questionnaire contains 25 questions, each section contains five parts in which self-concept is graded from definitely negative to definitely positive (five degrees). It means that the most positive answer is scored as five, and the most negative answer gets score one. In fact, this questionnaire measures the self-concept by the means of Likert scale and with a score of one through five (definitely positive, positive, neutral, negative, and definitely negative). Therefore, the definitely positive self-concept is scored 125 and the definitely negative self-concept is scored 25 . These scores are proposed for diagnosing self-concept: zero through 25 , definitely negative; 26 through 50 , negative; 51 through 75, neutral; 76 through 100, positive; and 101 through 125 , definitely positive. Samadi et al. self-efficacy standard questionnaire have also been developed on the Likert scale with 17 questions with five options from totally agree to totally disagree for each question, and scores ranging from one to 5.17 as the lowest score and score of 85 as the highest score (19). The points of the questions No. 1, 3, 8, 9, 13, and 15 increases from right to left and the points of the rest questions from left to right (it is reversed in the translated questionnaire), and the direction of the positive and negative sentences are also considered. This scale does not have any certain conditions for performing and restrictions of different ages does not apply for it. The data were divided into three groups. The points lower than 40 indicates poor self-efficacy; 40 to 63 , average self-efficacy; and 63 and higher, high self-efficacy To conduct this study, at first, researcher obtained an official letter of introduction from Faculty of Nursing and
Midwifery, Islamic Azad University, Isfahan (Khorasgan) Branch, Isfahan, Iran, and also from the research deputy of Ahvaz University of Medical Sciences, Ahvaz, Iran. After being reviewed by the committee for research and ethics and receiving the code of ethics, orders were issued for the study to be conducted in the selected medical centers. Next, the researcher introduced himself to the relevant authorities and explained the goals of the study for them. Then he attended at the hemodialysis units of the selected hospitals in various working shifts and in different days of the week and after expressing the goals and getting the consent of the research units, he explained how to complete the questionnaire and assured the participants about the confidentiality. Then he distributed the questionnaire and collected the data. In the case of uneducated patients, the researcher himself asked the questions from the patients and wrote their answers in the questionnaire. When completing the questionnaire, in order to answer the patient's possible questions unvaryingly, the researcher was present at the patient's bed, and collected the questionnaires on the same day. Finally, data were analyzed using descriptive and inferential statistics and by the means of Mann-Whitney statistics tests, Kruskal-Wallis tests, and Spearman's Correlation Coefficient in the SPSS 22 (IBM Corporation, New York, United States). The formula for determining sample size was as follows:

\section{Equation 1.}

$$
n=\frac{\left(Z_{1}-\frac{\alpha}{2}\right)^{2} \delta^{2}}{d^{2}}
$$

\section{Results}

The findings showed that patients had a mean age of $52.76 \pm 12.74$ with $54 \%$ being male and $46 \%$ being female. The majority of cases (67\%) were married. In addition, $31 \%$ of the patients had three to four children and $36.5 \%$ had five or more children. In terms of education, $24.5 \%$ of participants were uneducated and $29 \%$ only had been to primary school. In the case of income, $45.5 \%$ of participants reported their income as lower than their needs and $54.5 \%$ reported it as enough for their needs (Tables 1 and 2 )

In fact, the mean duration of treatment was $2.93 \pm 3.57$ years and mean duration of disease was $6.50 \pm 8.40$ years. Among the entire participants, the duration of hemodialysis in $(36 \%)$ of them ranged from one to three years. The duration of disease was less than five years in for $40 \%$ of participants. The duration of disease was less than five years in the majority of participants (25\%), and their duration of treatment was one to three years. In addition, the mean duration of dialysis was $0.43 \pm 3.56$ hours (Table 3 ). 
Jafari M et al.

Table 1. Demographic Information of Patients a

\begin{tabular}{lc}
\hline Demographic Information & Values \\
\hline Age, $\mathbf{y}$ & \\
$<30$ & $11(5.5)$ \\
$31-40$ & $28(14)$ \\
$41-50$ & $45(22.5)$ \\
$51-60$ & $51(25.5)$ \\
$>60$ & $65(32.5)$ \\
\hline
\end{tabular}

\section{Sex}

Male $92(46)$

Female

$108(54)$

Total

$200(100)$

\section{Marital Status}

$\begin{array}{lc}\text { Married } & 134(67) \\ \text { Not married } & 20(10) \\ \text { Divorced } & 12(6) \\ \text { Husband/wife passed away } & 34(17)\end{array}$

\section{Occupation}

Employee

Worker

$13(6.5)$

Housekeeper

$83(41.5)$

Retired

$30(15)$

Freelancer

In school/university student

Unemployed

\section{Income}

Lower than the needs

$91(45.5)$

Enough for the needs

$109(54.5)$

\section{Education}

$\begin{array}{lc}\text { Uneducated } & 49(24.5) \\ \text { Primary school } & 58(29) \\ \text { Guidance school } & 35(17.5) \\ \text { High school } & 44(22) \\ \text { University } & 14(7)\end{array}$

\section{Number of Children}

\begin{tabular}{lc}
0 & $20(10)$ \\
$1-2$ & $44(22)$ \\
$3-4$ & $63(31.5)$ \\
$\geq 5$ & $73(36.5)$ \\
Place of Living & \\
Urban & $155(77.5)$ \\
Rural & $45(22.5)$ \\
Total & $200(100)$ \\
\hline
\end{tabular}

a Data are presented as No. (\%).
Table 2. Information About the Disease and Treatment of Samples ${ }^{\mathrm{a}}$

\begin{tabular}{lc}
\hline Variable & Values \\
\hline Duration of disease, $\mathbf{y}$ & \\
$<1$ & $38(19)$ \\
$1-3$ & $72(36)$ \\
$3-6$ & $48(24)$ \\
$6-9$ & $25(12.5)$ \\
$>9$ & $17(8.5)$
\end{tabular}

The duration of treatment with

hemodialysis, $y$

\begin{tabular}{lc}
$<5$ & $88(44)$ \\
$5-10$ & $53(26.5)$ \\
$10-15$ & $38(19)$ \\
$15-20$ & $13(6.5)$ \\
$>20$ & $8(4)$ \\
Total & $200(100)$ \\
The cause of disease & \\
\hline Blood pressure & $89(44.5)$ \\
\hline Diabetes & $59(29.5)$ \\
\hline Renal and urinary tract diseases & $38(19)$ \\
\hline Infections & $9(4.5)$ \\
\hline Medications & $1(0.5)$ \\
Other & $4(2)$ \\
The duration of each dialysis session, $\mathbf{h}$ & \\
\hline Twice a week & $25(12.5)$ \\
\hline Three times a week & $175(87.5)$ \\
\hline a Data are presented as No. (\%). & \\
\hline
\end{tabular}

Table 3. Mean Score and Self-Efficacy in Research Units

\begin{tabular}{lcc}
\hline & Number & Scores, Mean \pm SD (Range) \\
\hline Self-Efficacy & 200 & $52.37 \pm 10.81(23-81)$ \\
Self-Concept & 200 & $76.61 \pm 7.029(55-107)$ \\
\hline
\end{tabular}

The mean scores of self-efficacy and self-concept in the subjects are shown in Table 3. The mean score of self-concept in participants of the study was 76.61 and the mean score of self-efficacy was 52.37 . Table 4 shows the distribution of absolute and relative frequency of research units according to the level of self-concept and self-efficacy.

In fact, the majority of participants (18.5\%) had a good level of self-efficacy (average) and were definitely positive in self-concept. The lowest frequency (6.5\%) was seen in the participants with definitely positive self-concept and poor self-efficacy. None of the participants was listed in the negative or definitely negative group. The self-concept of the participant was in an acceptable level, but their self-efficacy ranged from average to poor. 
Jafari M et al.

\begin{tabular}{lcccc}
\hline \multicolumn{2}{l}{\begin{tabular}{l} 
Table 4. The Distribution of Absolute and Relative Frequency of Research Units According to the Level of Self-Concept and Self-Efficacy \\
\hline The level of Self-concept
\end{tabular}} & \multicolumn{2}{c}{ The Level of Self-Efficacy, No. (\%) } \\
\cline { 2 - 5 } & Poor & Average & Good & Total \\
\hline Neutral & $33(16.5)$ & $25(12.5)$ & $14(7)$ & $72(36)$ \\
Positive & $22(11)$ & $25(12.5)$ & $16(8)$ & $63(31.5)$ \\
Definitely positive & $13(6.5)$ & $15(7.5)$ & $37(18.5)$ & $65(32.5)$ \\
Total & $68(34)$ & $65(32.5)$ & $67(33.5)$ & $200(100)$ \\
\hline
\end{tabular}

\section{Discussion}

Findings showed that $34 \%$ of the participants had poor self-efficacy; $32.5 \%$ had average and $33.5 \%$ had good selfefficacy. Moreover, $36 \%$ of participants had neutral selfconcept, 31.5\% positive self-concept, and 32.5\% definitely positive self-concept. The majority of participants (18.5\%) had good (average) self-efficacy and definitely positive self-concept. In this case, the result of this study is consistent with the results of a study by Huang and Tsai who analyzed the abilities of patients with ESRD and reported the self-efficacy as average in most of the participants (36\%). In the findings of this study, only 5.33\% of the participants had high efficacy. Hence, in caring of patients on hemodialysis who live in certain circumstances, it is important to consider that high self-efficacy is associated with the ability of adapting to different circumstances and controlling threatening situations. Hence, the treatment team should pay more effort to increase the selfefficacy of these patients. In addition, 31.5\% of our participants had positive self-concept, $32.5 \%$ had definitely positive self-concept, and no one had negative or definitely negative self-concept. The findings of Ghodusi's study on the effects of the self-esteem on self-concept and its related factors in patients with multiple sclerosis showed that the most of the patients had average self-esteem (16). In addition, the value of the correlation coefficient between self-efficacy and self-concept was $0.495(\mathrm{P}<$ 0.001). Therefore, a direct and significant correlation was observed between self-efficacy and self-concept, so that with an increase in self-concept the level of self-efficacy is also increased $(\mathrm{P}<0.05)$. Moreover, there was a significant difference between the self-efficacy among different age groups $(\mathrm{P}<0.05)$. The best level of self-efficacy was in those of younger than 30 and then in the age range of 31 to 40 with the self-efficacy mean score of 64.55 and 54.61 , respectively. The findings also showed that the selfefficacy mean score in those who were older than 60 was lower than other groups (score, 49.55). It seems that with aging and decreasing physical and mental abilities, and also conflicting with a chronic disease, the individual's ability to achieve optimal self-efficacy reduces gradually. In addition, the mean score of self-efficacy was higher in those patients who were on dialysis twice a week than in those who were on dialysis three times a week (scores of 58.20 and 51.54 , respectively). The mean score of self-con- cept was higher in patients who were on dialysis twice a week than in those who were on dialysis three times a week (score, 79.52 vs. 76.19). Due to the problems caused by ESRD, treatment periods, ongoing medical care, complications of the disease and treatment, and lack of physical strength, and expended time and money, the patients on hemodialysis face with many problems. These problems reduce their activities and capabilities, and undermines their ability for dealing with the issues and achieving their goals and success. Therefore, the belief in self-efficacy fades in them. This finding is in accordance with the results of a study by Davis et al. who examined the self-efficacy of therapy in patients with obstructive lung disease in the United States (19). The other findings of our research showed that the mean score of self-concept in patients with less than one-year duration of treatment was significantly higher than in others (score, 80). On the other hand, no significant difference was seen in self-concept between the other groups of patients. Although the prevalence of mental health problems may be greater in the first years of disease and dialysis, with the passing of time, self-concept and mental status of patients remained almost in a constant state. However, the results of some investigations, consistent and aligned with the results of this study, showed that physical function including self-efficacy in the patients with chronic and hard-to-cure diseases decreases over time although their mental health status remains in a contestant state. This can be due to compatibility and effective coping that occurs in these patients because patients are introduced to stressors and coping strategies during treatment and experience the major changes of compatibility with the problems. Moreover, as the distance between the real and ideal self in the individual decreases, the body management behaviors increases. In fact, positive self-concept is usually formed in the field of developing talents and abilities. By designing and implementing patient-focused interventions, the nurses can provide the ground to improve the self-efficacy of these patients, especially in acquiring skills related to self-care in increasing selfpracticed ability.

Some of the limitations of the study are as follows: the emotional status of the participants in the process of completing the questionnaire; the possible factors (such 
as psychologic, social, and environmental factors), which may affect the mindfulness of the participants during the answering phase; the individual, social, and economical differences; the different cultural and theological roots; various expectations and perceptions of one's self; and finally, accuracy and honesty of the participants in answering the questions.

\section{Acknowledgements}

We appreciate the President and the Research Deputy of the Jundishapur university of medical sciences. In addition, our heartfelt gratitude goes to Dr. Heydar Ali Abedi that this study could have never been possible without his help.

\section{Authors' Contributions}

Marziyeh Jafari: Study design, data collection/analysis, drafting manuscript, and supervision. Reza Mannani: administrative/technical/material support and critical revisions for important intellectual content. Kourosh Zarea: administrative/technical/material support and supervision.

\section{References}

1. Partridge KA, Robertson N. Body-image disturbance in adult dialysis patients. Disabil Rehabil. 2011;33(6):504-10.

2. Hyre AD, Cohen AJ, Kutner N, Alper AB, Dreisbach AW, Kimmel PL, et al. Psychosocial Status of Hemodialysis Patients One Year After Hurricane Katrina. Am J Med Sci. 2008;336(2):94-8.

3. Cukor D, Coplan J, Brown C, Friedman S, Cromwell-Smith A, Peterson RA, et al. Depression and Anxiety in Urban Hemodialysis Patients. Clin j Am Soc Nephrol. 2007;2(3):484-90.

4. Ricks J, Molnar MZ, Kovesdy CP, Kopple JD, Norris KC, Mehrotra $\mathrm{R}$, et al. Racial and ethnic differences in the association of body mass index and survival in maintenance hemodialysis patients. Am J Kidney Dis. 2011;58(4):574-82.

5. Smeltzer SC, Bare BG. Brunner and sudarths textbook of Medical Surgical Nursing.Philadelphia: Lippincot CO; 2010.
6. Hoffman AJ, von Eye A, Gift AG, Given BA, Given CW, Rothert M. Testing a theoretical model of perceived self-efficacy for cancerrelated fatigue self-management and optimal physical functional status. Nurs Res. 2009;58(1):32-41.

7. Kaplan HI, Sadock BJ. Anxiety Disorder overview. 9th edNewYork: Williams and Wilkins; 2007.

8. Burdmann EA, Chan YM, Zalilah MS, Hii SZ. Determinants of Compliance Behaviours among Patients Undergoing Hemodialysis in Malaysia. PLoS ONE. 2012;7(8):e41362.

9. Horigan AE, Schneider SM, Docherty S, Barroso J. The experience and self-management of fatigue in patients on hemodialysis. Nephrol Nurs J. 2013;40(2):113-22.

10. Poorshaban M, Gholamnejad M, Yekta Z. The effect of education diet on the severity of the physical problems of CKD. Nurs Res J. 2014;9(2):47-55.

11. Chan R, Brooks R, Erlich J, Gallagher M, Snelling P, Chow J, et al. Studying psychosocial adaptation to end-stage renal disease: the proximal-distal model of health-related outcomes as a base model.J Psychosom Res. 2011;70(5):455-64.

12. Theofilou P. Quality of life and mental health in hemodialysis and peritoneal dialysis patients: the role of health beliefs. Int Urol Nephrol. 2012;44(1):245-53.

13. Sarnak MJ, Tighiouart H, Scott TM, Lou KV, Sorensen EP, Giang LM, et al. Frequency of and risk factors for poor cognitive performance in hemodialysis patients. Neurology. 2013;80(5):471-80.

14. Celik G, Annagur BB, Yilmaz M, Kara F. Findings of multidimensional instruments for determining psychopathology in diabetic and non-diabetic hemodialysis patients. Int J Clin Exp Med. 2012;5(4):346-54.

15. Armaly Z, Farah J, Jabbour A, Bisharat B, Abd-El Qader A, Saba S, et al. Major depressive disorders in chronic hemodialysis patients in Nazareth: identification and assessment. Neuropsychiatr Dis Treat. 2012:329-38.

16. Ghodusi M, Sharifi N, Heydari M, Hosseini F. Self-esteem and the related factors in multiple sclerosis patients. Publications of the center for Nursery Cares Reseach in the Tehran University of Medical sciences Iran Nursery Publications. 2012;25(75):14-22.

17. Nyakrouy A. . Relationship between self-efficacy and mental health of high school students in BaBol.. Tehran: Tabatabay Allameh University; 2003.

18. Samadi A, Safavi M. , Mahmoudi M. self-efficacy and its relation to quality of life for people with diabetes type 2 .J Med Sci Islamic Azad Univ Tehran.;150(2):148-53.

19. Davis D,Fedor D,Parson K,Herold M.The development of self-efficacy during aviation training journal of organizational BEHAVIOR;2000.21(8):857-871. 